\title{
An Approach on Place Attachment, Involvement and Behavioural Intentions in Iberian Marketing Contexts: The Case of Galicia-North Portugal Euroregion: An Abstract
}

\author{
Bruno Sousa and Cláudia Simões
}

\begin{abstract}
This study aims at gaining a deeper understanding of customer profiling and behaviour in Iberian marketing and cross-border tourism destinations, in specific the case of Galicia-North of Portugal Euroregion. The study is developed under a niche marketing perspective. It is our view that niche marketing is not confined to the limits of national markets. Previous studies suggest that cross-border regions are an attractive notion, yet they require further theoretical and empirical research. There is still a gap in the understanding of destination management in cross-border regions and the customer profile and motivations. Overall this research attempts to produce a deeper understanding of the profile and behaviour of consumers in tourism settings, addressing the predisposition for the destination in specific contexts (i.e. Galicia-North of Portugal Euroregion). The study proposes influencers of customer behaviour and attitudes (e.g. involvement, place attachment and tourist satisfaction) in the context of cross-border tourism destinations. Under an interdisciplinary perspective, this research brings together inputs from marketing, tourism and local economics. A theoretical model is developed specifying antecedents of satisfaction and loyalty in cross-border tourism regions. Implications for future research are also presented.
\end{abstract}

References Available Upon Request

\footnotetext{
B. Sousa $(\square)$

Polytechnic Institute of Cávado and Ave-IPCA, Barcelos, Portugal

e-mail: bsousa@ipca.pt

C. Simões

University of Minho, Braga, Portugal

e-mail: csimoes@eeg.uminho.pt 